\title{
Substance use among patients in specialized mental health services in Norway: prevalence and patient characteristics based on a national census
}

Helle Wessel Andersson ( $\square$ helle.wessel.andersson@stolav.no )

St.Olavs University Hospital https://orcid.org/0000-0002-2153-6088

Solfrid E. Lilleeng

The Norwegian Directorate of Health

Torleif Ruud

Akershus University Hospital and University of Oslo

Solveig Osborg Ose

SINTEF Technology and Society

Research article

Keywords: Mental health services, Psychiatric disorders, Substance use, Substance use disorders, Comorbidity, Prevalence, Patient characteristics, National census

Posted Date: December 3rd, 2019

DOI: https://doi.org/10.21203/rs.2.18095/v1

License: (9) This work is licensed under a Creative Commons Attribution 4.0 International License.

Read Full License

Version of Record: A version of this preprint was published at Nordic Journal of Psychiatry on September 18th, 2020. See the published version at https://doi.org/10.1080/08039488.2020.1817553. 


\section{Abstract}

Background: Most studies on substance use among psychiatric patients focus on patients within specific diagnostic categories. Less is known about substance use among the general psychiatric patient population. The aim of this study was to investigate the clinical and demographic variation in the prevalence of substance use among psychiatric in-patients and outpatients in Norway.

Methods: A national census in psychiatric institutions and outpatient clinics was conducted. Data were returned for 2,358 in-patients (response rate, $65 \%$ ) and 23,167 outpatients (response rate, $60 \%$ ). Substance use was measured based on substance use disorder diagnosis or reported substance use in the last four weeks (alcohol 2-4 days a week or illicit drug use). Regression analyses controlling for demographic and socio-demographic characteristics were carried out.

Results: Substance use was identified in $32.4 \%$ of in-patients and $13.9 \%$ of outpatients. The most frequently reported substances used were alcohol, sedatives and cannabis. Among in-patients, the prevalence of substance use was highest in patients with schizophrenia, personality disorders and anxiety disorders. Among outpatients, the prevalence was highest in patients with schizophrenia and other psychoses. In-patients with anxiety disorders and outpatients with schizophrenia and other psychoses had a significantly higher risk of substance use than other patients. In both samples, the prevalence of substance use was higher among males, 24-29-year-olds and the most socially deprived.

Conclusions: This study provides further knowledge about patients at risk for co-morbid substance abuse and poor treatment outcomes. Clinicians may consider targeting patients with severe mental illness, young males and those who are socially deprived in efforts to prevent emerging substance abuse and improve outcomes.

\section{Background}

The high prevalence of co-morbid substance use disorders (SUD) and mental health disorders documented in epidemiological research $[1,2]$ has also been found in studies of the psychiatric patient population. For instance, register-based studies reported that among patients with psychiatric disorders, rates for any lifetime SUD were $25 \%$ for anxiety and depression and $46 \%$ for personality disorders [3]. Recent research has suggested that among individuals with schizophrenia, even non-problematic drug use may increase the risk for developing SUD [4].

Most previous studies on substance use among psychiatric patients were carried out among patients within specific diagnostic categories, such as schizophrenia, bipolar disorders and major depression [510]. A strong association between severe mental disorders and SUD has been shown both among inpatients and outpatients [7], as well as among patients in acute departments [11, 12]. The most frequently reported substances used among patients with severe mental disorders were alcohol, cannabis, sedatives and stimulants $[3,11,12]$. In some studies, alcohol was found to be the most 
prevalent drug used across all psychiatric disorders [3], whereas other studies estimated the use of illicit substances to be more common than alcohol use among those with severe mental illness $[7,10]$.

While many studies have investigated co-morbid SUD among patients with severe mental illness, substance use in patients with less severe mental disorders, such as anxiety and affective disorders [13], has received less attention. One of the few studies conducted in a sample of patients drawn from the general psychiatric patient population indicated a higher prevalence of SUD among in-patients than outpatients, and particularly among patients with personality disorders [14]. However, this study did not report data on the type of substances used. Another study of a non-selected sample of patients receiving treatment in community mental health centres in Norway, where anxiety and affective disorders are common psychiatric disorders, identified SUD in $20 \%$ of the patients. This study also showed that having SUD was associated with a lower prevalence of anxiety and depression [15].

Despite previous research among psychiatric patients used different samples and different methods to identify substance use, and thus reported varying SUD prevalence rates, the findings regarding the characteristics of patients with substance use problems are consistent. Previous studies have shown that co-occurring mental disorders and SUD are associated with being male $[3,7,9,14]$, younger and single $[14,16]$. Moreover, research has demonstrated that psychiatric patients with SUD have less educational attainment $[3,14,17]$ and generally more adverse socio-economic characteristics [15].

The literature suggests that substance use in individuals with mental disorders is associated with higher levels of antisocial and behavioural challenges [14], more complicated recovery processes [15] and poorer outcomes $[18,19]$. To date however, research on the characteristics of patients with substance use in mental health services has mainly focused on delimited patient populations. The current study extends existing knowledge by investigating substance use among in-patient and outpatient psychiatric patients in a nationwide census.

\section{Aims of the study}

The aims of this study were to examine:

- the prevalence of substance use among in-patients and outpatients in the specialized mental health services;

- the substance use characteristics of these patients, in terms of psychiatric disorders and type of drug used most frequently; and

- the demographic (age and gender) and socio-demographic (education, income and marital status) characteristics of outpatients and in-patients with substance use compared with other patients.

We hypothesized that the prevalence of substance use would be higher among patients suffering from severe mental disorders compared with other mental disorders, and moreover, that substance use would 
be more prevalent among males than females, and among social deprived patients, in line with previous studies $[3,14]$.

\section{Methods}

\section{Setting}

In Norway, as in most other European countries [20], there are distinct mental health and SUD treatment departments. Specialized mental health services are owned on behalf of the state by four regional health authorities (RHAs), which are responsible for the provision of health services for the population in their area.Specialized mental health services are organized together with general hospital services in 19 health trusts. The services are mostly public, and the private health service providers have an operating agreement with the RHA [21]. General practitioners or other specialist health services make referrals of patients to mental health services. As in most Western countries, the services for people with mental disorders have gone through major changes in recent decades. There has been a reduction in the number of patients staying in psychiatric institutions, with most people with mental problems being provided with outpatient mental health services.

\section{Design}

A comprehensive national census of patients in mental health treatment, commissioned and financed by the Norwegian Directorate of Health, was carried out by the SINTEF Research Foundation. The census was conducted in all psychiatric wards and departments (including acute wards) providing in-patient treatment on a specific date, and in all clinics and departments (including community mental health centres), providing outpatient treatment during a specific 14-day period. Each patient's clinician was responsible for completing the form. Because the study had a national cross-sectional design with high coverage, it was possible to estimate the point prevalence for the entire patient population. The Regional Committee for Medical and Health Research Ethics (reg. no. 2012/848) approved the current study.

\section{Data collection}

All in-patients on a given day (20 November 2012) and all outpatients who had one or more consultations during a 14-day period (15-28 April 2013) were the targeted study participants. All mental health services in public and private sectors were invited to participate in the census. Several months prior to the mapping, the service managers and clinicians received information describing the project and the data collection procedures. The clinicians completed one form per patient. The registration forms included a wide range of topics, including main and secondary diagnoses (International Classification of Diseases, ICD-10), demographics and socio-demographic characteristics. The clinicians were encouraged to invite the patient to participate in completing the form, and over half of the in-patients (55\%) and outpatients 
(57\%) did so. The completed forms were returned by registered mail to a firm that performed scanning and coarse quality control of the data. The project team performed further quality control of the data files.

\section{Sample}

In total, 94 of the 104 psychiatric in-patient departments and 107 of the 110 psychiatric outpatient clinics in the health trusts participated in the census. Most of the units that did not participate were small, and they cited a lack of time as their reason for not participating. Non-participating clinics comprised $1 \%$ of all outpatient consultations, and non-participating institutions comprised $4 \%$ of all in-patient days during 2012. Data were returned for 2,358 in-patients and 23,167 outpatients. Based on data from the National Patient Register on the number of patients attending the mental health services during the inclusion periods, the response rates were estimated to be $65 \%$ of 3,618 in-patients and $60 \%$ of 38,904 outpatients.

\section{Variables}

\section{Psychiatric diagnoses}

The following diagnostic categories were used: Schizophrenia (F20), Other psychoses (F22-25, F28-F29), Bipolar disorder (F31), Depression (F32-F34), Anxiety (F40, F41), PTSD (F43.1), Eating disorders (F50), Personality disorders (F60, F61), Other psychiatric diagnoses or unspecified (all other F-diagnoses).

\section{Substance use}

Substance use was measured based on the recorded ICD-10 diagnoses of SUD (F10-F19), or reported substance use in the last four weeks preceding treatment, and included the following response options: (1) Less than once a week; (2) almost weekly; (3) 2-4 times a week; (4) almost daily. For individuals with psychiatric disorders, regular alcohol use and occasional use of illicit drugs may pose a risk of worsening psychiatric symptoms [22, 23] and development of problematic substance use [4]. Based on a recorded SUD diagnosis and reported substance use, we constructed a dichotomized variable, with a value of 1 for the presence of a SUD diagnosis or reported regular alcohol use (2-4 times a week or more/occasional illicit drug use), and 0 for no SUD diagnosis and non-regular alcohol use and no illicit drug use. Type of drug used was categorized as: alcohol, opioids, cannabis, sedatives, stimulants, or multiple substance use.

\section{Demographic and socio-demographic characteristics}

In addition to gender and age, we included education (where low education corresponds to only primary school, medium education to secondary school and high education to university or other higher education), income (with the categories income from labour, health-related benefits, other economic support) and marital status (grouped in the three categories married/cohabitant/partner, separated/divorced/widow(er) and single/unmarried). 


\section{Data analyses}

The binary nature of the substance use variable as the dependent variable implies a logit model. The STATA software package was used for all analyses (Stata/SE 14.2 for Windows; StataCorp LP, College Station, TX). We estimated 3 models; the first model included only diagnoses (Model 1), gender and age were added in the second model (Model 2), and the third model also included the socio-demographic variables level of education, main source of income and marital status (Model 3).

\section{Results}

\section{Prevalence of substance use}

The prevalence of substance use is presented in Table 1. Substance use was identified in 390 in-patients (16.4\%) based on ICD-10 diagnosis (F10-F19), and in an additional 373 in-patients (15.8\%) based on recorded substance use. The total prevalence of substance use among in-patients was $32.4 \%$. Among outpatients, substance use was identified in 1,300 outpatients $(5.6 \%)$ based on ICD-10 diagnosis (F10F19), and in an additional 1,910 outpatients (8.2\%) based on recorded substance use. The total prevalence of substance use among outpatients was $13.9 \%$.

Substance use was identified in $42.0 \%$ of all male in-patients, whereas the corresponding prevalence in female in-patients was $24.0 \%$. Male patients diagnosed with schizophrenia had almost twice the risk of substance use compared with female patients suffering from the same mental illness. The same result appeared in in-patients diagnosed with bipolar disorders, with substance use being three times more prevalent for male than for female patients.

Substance use was prevalent in $20.0 \%$ of all male outpatients, versus only $10.1 \%$ of female outpatients. Consistent with in-patient results, male outpatients diagnosed with schizophrenia had more than twice the risk of substance use than female patients suffering from the same mental illness. The same malefemale difference in prevalence of substance use also appeared among patients with bipolar disorders and depression. Among patients with personality disorders, the prevalence was roughly similar for females $(13.4 \%)$ and males (16.4\%). Within the various categories of diagnoses, the prevalence of substance use was lowest among those with eating disorders (8.3\%), and few of these patients were men (3.2\%).

\section{Substance use characteristics}

Substance use characteristics are presented in Table 2. Among in-patients, cannabis and sedatives were the most frequently used substances, accounting for $12.3 \%$ and $10.9 \%$ of the total prevalence of substance use, respectively. The use of any illegal substances, such as cannabis (23.8\%) and stimulants (20.8\%), was more prevalent among patients diagnosed with schizophrenia than patients with other psychiatric diagnoses. 
The substance most frequently used among patients diagnosed with anxiety disorders, personality disorders, and PTSD was sedatives, with rates of $21.0 \%, 17.9 \%$ and $17.3 \%$, respectively. Among patients with bipolar disorders, use of alcohol (11.3\%) was more prevalent than use of any illegal substance.

Among outpatients, use of alcohol was more prevalent (6.3\%) than use of any illegal substances. In patients diagnosed with depression, who represented the largest diagnostic outpatient group, alcohol use was more prevalent $(6.1 \%)$ than any illicit drug use. Cannabis and sedatives were the most frequently reported illegal substances used, accounting for $4.0 \%$ and $3.7 \%$ of the total prevalence of substance use, respectively. Patients with schizophrenia had higher use of illegal substances, particularly stimulants $(11.2 \%)$ and cannabis $(9.2 \%)$, than patients with other psychiatric diagnoses.

\section{Demographic and socio-demographic characteristics}

Table 3 shows that the prevalence of substance use was highest among in-patients aged under 40 years, particularly among those aged $24-29$ years (43\%). Among patients in outpatient treatment settings, there were relatively small differences in prevalence of substance use between age groups, with rates of $13 \%$ and $18 \%$ for those aged under 40 years and those aged $60-69$ years, respectively. Patients with lower levels of education (primary school or less) had a higher prevalence of substance use than those with higher levels of education (university), both among in-patients ( $36 \%$ and $22 \%$, respectively) and outpatients (17\% and $10 \%$, respectively). Among both in-patients and outpatients, those with healthrelated benefits had a higher prevalence of substance use than those with income from labour or other sources. Finally, being married, cohabiting or having a partner implied a lower prevalence of substance use than having any other marital status.

\section{Regression results}

Table 4, Figures 1 and Figure 2 provide the results of multivariate logistic regressions of the association between patient characteristics and odds ratios for substance use. Among in-patients (Figure 1), the differences in substance use prevalence in diagnoses (Model 1) were reduced when we added demographic (Model 2) and socio-demographic (Model 3) characteristics. Patients with anxiety disorders had significantly higher substance use prevalence than patients with schizophrenia when we controlled for demographic and socio-demographic characteristics.

Among outpatients (Figure 2), demographic and socio-demographic characteristics explained fewer of the differences in substance use prevalence between the diagnostic categories. Patients diagnosed with schizophrenia and patients with other psychoses did not differ significantly in substance use prevalence in Model 3.

Male patients had a higher prevalence of substance use in all model specifications. The youngest age groups (i.e., 18-23 years and 24-29 years) had higher substance use prevalence among in-patients, while the opposite was found among outpatients in Model 3. 
The socio-economic differences found in the descriptive analyses were also valid in the regression analyses; lower education, receiving benefits rather than deriving income from labour, and not having a partner implied higher substance use prevalence in both samples, even when controlling for demographic characteristics and diagnoses.

\section{Discussion}

This nationwide census conducted in psychiatric institutions and outpatient clinics showed that substance use occurred more frequently among in-patients than outpatients, and among patients with more severe mental illness in both treatment settings. Among in-patients, the most frequently used substances were cannabis and sedatives, whereas alcohol was more prevalent than use of any illegal substances among outpatients. In both samples, substance use was more prevalent in young males and the most socially deprived.

The higher prevalence of both SUD diagnosis and substance use found among in-patients aligns with previous studies $[7,14]$, and suggests that in in-patient treatment, there is a different patient case mix with relatively higher rates of severe mental illness, such as schizophrenia and major depression, which are typically associated with higher rates of co-occurring SUD $[3,7,10]$.

A number of studies have documented that substance use and SUD are under-reported and underdiagnosed in psychiatric treatment settings [24-26]. Moreover, a recent Norwegian Board of Health study highlighted the existing deficiencies in specialized mental health services regarding the investigation and examination of patients with possible concurrent SUD [27]. The accuracy of reported substance use, such as in the present study, may depend on several factors, including whether substance use issues were part of the routine clinical assessment, and the patients' responses when asked about substance use. Such conditions may vary between treatment settings [28]. It is possible that the intensive treatment and close monitoring of patients in in-patient treatment allowed clinicians to make a more thorough evaluation of the patients' substance use behaviour, resulting in higher identification rates than in outpatient treatment settings. The under-identification of substance use may also be related to insufficient knowledge of substance abuse issues among clinicians [25] and/or the lower status of working with substance users [29].

Methodological and sample differences complicate the comparison of results between studies. Of the few studies conducted in general psychiatric outpatient and in-patient treatment settings, Rush and Koegl's study [14], conducted in in-patient and outpatient mental health treatment facilities in Ontario, is most comparable with the present work. They reported a prevalence of SUD (based on diagnosis) among in-patients of $15.6 \%$, which is similar to the point prevalence of recorded SUD diagnosis in the current inpatient sample (16.4\%). However, the current SUD rate of $5.6 \%$ based on recorded diagnosis found in the outpatient sample is relatively low in comparison with the $11 \%$ SUD prevalence among outpatients reported by Rush and Koegl [14]. 
When comparing the prevalence of substance use in psychiatric patients across countries, one should take into account possible between-country differences in the organization and delivery of health services. For example, community addiction services have a more prominent role in Norway and other European countries than in the USA [20]. Moreover, in Norway, community-integrated mobile teams offer dual treatment for individuals with mental illness and substance abuse.

Consistent with results from other studies of psychiatric patients, the present results showed that alcohol, cannabis and sedatives were the most commonly used substances [3, 11, 12]. Also in line with previous reports $[7,10]$, use of illegal substances, particularly cannabis, occurred more frequently among inpatients than outpatients, and, as hypothesized, among patients with the most severe mental disorders (e.g., schizophrenia and other psychoses). Although the association between use of illicit drugs and severe mental illness is frequently recognized in the literature, the basis for the link is still being discussed [30-32]. For example, research concerning the association between schizophrenia and SUD has suggested a common genetic risk [33], or that patients with a genetic risk for schizophrenia are more vulnerable to substance use [34].

As hypothesized, and consistent with previous clinical studies, the current results showed that substance use occurred twice as often among men than among women [e.g., 7, 9]. The prevalence of substance use was particularly high among in-patient young males, aged 18-29 years. This finding may reflect the high prevalence of substance-induced mental disorders among in-patients, which is associated with symptom onset at a younger age $[7,35]$. Our results also confirmed the socio-demographic differences in prevalence of substance use reported elsewhere [3].

After adjusting for demographic and socio-demographic variables in multivariate analysis, the differences in prevalence rates of substance use between the psychiatric diagnostic categories among inpatients were reduced, indicating that substance use was associated with greater levels of social and economic disadvantages, as reported elsewhere [3]. The present results showed that independent of demographic and socio-demographic factors, in-patients with anxiety disorders, who constituted a relatively small subsample of those in in-patient treatment $(n=62)$, had the highest prevalence of substance use, particularly alcohol and sedatives; this suggests that this subsample constituted a group of patients who used substances to cope with severe anxiety symptoms [36, 37].

A Canadian study found that socio-demographic characteristics did not explain differences in substance use prevalence among in-patients, while the opposite was found for outpatients [14]. Our results imply that socio-demographic characteristics explain differences in prevalence of substance use among both in-patients and outpatients. Furthermore, Rush and Koegl [14] found that among outpatients, sociodemographic variables such as young age, being male, single, and having a low level of education were associated with prevalence of substance use. Our results indicate that outpatients in the youngest age group (18-23 years old) were at lower risk of substance use than patients older than 24 years. However, we also found that less of the difference in prevalence of substance use between psychiatric disorders was explained by socio-demographic variables among outpatients than in-patients, reflecting a relatively 
homogeneous outpatient population. Differences in access to health services between countries, and subsequent differences in patient composition in specialty mental health services might explain the noncongruent findings.

\section{Strengths And Limitations}

A major strength of this study is the large unselected sample of psychiatric patients. Moreover, the current study represents one of very few studies reporting the prevalence of substance use among in-patients and outpatients in specialty mental health services.

There are several limitations. The reliability of substance use reporting in the current study may be a limitation. The current measure of substance use was based on combined information from the clinician's recordings of a co-occurring SUD diagnosis and reports of the patients' use of alcohol and illicit substances during the four weeks preceding treatment. Research shows that substance use problems are under-reported and underdiagnosed in mental health care [24-26]. The reliability of substance use reporting is likely to depend on the patient-therapist relationship, and on the extent to which the patient participated in completing the form. Information about which patients participated in completing the form was not included in the current analysis. In addition, the study design emphasizes patients in longterm treatment and patients with more frequent consultations, as they were more likely to be receiving treatment at any given time. One possible consequence of this is that the census included relatively more patients who were familiar with mental health services, and if so, those who were more likely to report on their substance use [28].

Moreover, reported substance use may not fulfil the diagnostic criteria for SUD, thus the current measure of substance use does not represent a clinically significant psychiatric co-morbidity. Consequently, the results from the present study may not be comparable with research using clinically validated substance use measures. Additionally, the current results may not generalize to countries with different structures of mental health and addiction treatment services. However, it is reasonable to believe that our findings can generalize to systems with public health services with separated rather than integrated specialized treatment for mental illness and SUD.

\section{Conclusion And Implications}

The current study included patients from the general psychiatric patient population to provide further knowledge about patients at risk for co-morbid substance abuse. Patient characteristics associated with substance use include having a severe mental illness, being a young male and being socially deprived. Clinicians may want to target patients with these characteristics in efforts to identify and prevent emerging substance abuse and improve treatment outcomes. Future research should determine the clinical consequences of substance use in the general psychiatric patient population and investigate whether efforts designed to identify and manage substance use are effective in improving the treatment process and outcome. 


\section{List Of Abbreviations}

ICD: International Classification of Diseases; RHA: regional health authority; SUD: substance use disorders.

\section{Declarations}

\section{Ethics approval and consent to participate}

This study comprised full mapping of patients in all psychiatric wards and departments conducted on behalf of the national health authorities. Each patient's clinician was responsible for completing one form per patient. Written consent was obtained from the patients, but the clinician completed the forms for all patients, including those who did not give their consent. In the latter case, no personal identification number was collected. Data was anonymized for the analyses. The study was approved by The Regional Committee for Medical and Health Research Ethics (reg.no. 2012/848).

\section{Consent for publication}

Not applicable

\section{Availability of data and materials}

The data that support the findings of this study are available from author SOO upon reasonable request.

\section{Competing interests}

The authors declare that they have no competing interests.

\section{Funding}

No funding was provided for this study.

\section{Authors' contributions}

HWA participated in designing the study, drafted the manuscript and completed final edits of the manuscript. SEL participated in designing the study, supervised the analyses and interpretation of data, and provided critical review of the manuscript. TR critically reviewed and revised the manuscript. SOO was responsible for the idea and design of the study, carried out the statistical analyses and contributed in drafting the manuscript. All authors read and approved the final manuscript as submitted. 


\section{Acknowledgements}

Not applicable

\section{References}

1. Kessler RC. Impact of substance abuse on the diagnosis, course, and treatment of mood disorders: the epidemiology of dual diagnosis. Biol Psychiatry. 2004;56. https://doi.org/10.1016/j.biopsych.2004.06.034

2. Lai HMX, Cleary M, Sitharthan T, Hunt GE. Prevalence of co-morbid substance use, anxiety and mood disorders in epidemiological surveys, 1990-2014: a systematic review and meta-analysis. Drug Alcohol Depend. 2015;154:1-13. https://doi.org/10.1016/j.drugalcdep.2015.05.031

3. Toftdahl NG, Nordentoft M, Hjorthøj C. Prevalence of substance use disorders in psychiatric patients: a nationwide Danish population-based study. Soc Psychiatry Psychiatr Epidemiol. 2016;51(1):12940. https://doi.org/10.1007/s00127-015-1104-4

4. Petersen SM, Toftdahl NG, Nordentoft M, Hjorthøj C. Schizophrenia is associated with increased risk of subsequent substance abuse diagnosis: a nation-wide population-based register study. Addiction. 2019. https://doi.org/10.1111/add.14746

5. Di Florio A, Craddock N, van den Bree M. Alcohol misuse in bipolar disorder. A systematic review and meta-analysis of co-morbidity rates. Eur Psychiatry. 2014;29(3):117-24.

https://doi.org/10.1016/j.eurpsy.2013.07.004

6. Helseth V, Lykke-Enger T, Johnsen J, Waal H. Substance use disorders among psychotic patients admitted to in-patient psychiatric care. Nord J Psychiatry. 2009,63(1):72-7.

https://doi.org/10.1080/08039480802450439

7. Hunt GE, Large MM, Cleary M, Lai HMX, Saunders JB. Prevalence of co-morbid substance use in schizophrenia spectrum disorders in community and clinical settings, 1990-2017: systematic review and meta-analysis. Drug Alcohol Depend. 2018;191(1):234-58. https://doi.org/10.1016/j.drugalcdep.2018.07.011

8. Kavanagh DJ, Waghorn G, Jenner L, Chant DC, Carr V, Evans M, et al. Demographic and clinical correlates of co-morbid substance use disorders in psychosis: multivariate analyses from an epidemiological sample. Schizophr Res. 2004;66(2-3):115-24. https://doi.org/10.1016/S09209964(03)00130-0

9. Messer T, Lammers G, Müller-Siecheneder F, Schmidt R-F, Latifı S. Substance abuse in patients with bipolar disorder: a systematic review and meta-analysis. Psychiatry Res. 2017;253:338-50. https://doi.org/10.1016/j.psychres.2017.02.067

10. Nesvåg R, Knudsen GP, Bakken IJ, Høye A, Ystrom E, Surén P, et al. Substance use disorders in schizophrenia, bipolar disorder, and depressive illness: a registry-based study. Soc Psychiatry Psychiatr Epidemiol. 2015;50(8):1267-76. https://doi.org/10.1007/s00127-015-1025-2 
11. Fløvig JC, Vaaler AE, Morken G. Substance use at admission to an acute psychiatric department. Nord J Psychiatry. 2009;63(2):113-9. https://doi.org/10.1080/08039480802294787

12. Helseth V, Samet S, Johnsen J, Bramness JG, Waal H. Independent or substance-induced mental disorders? An investigation of co-morbidity in an acute psychiatric unit. J Dual Diagn. 2013;9(1):7886. https://doi.org/10.1080/15504263.2012.749142

13. Jané-Llopis E, Matytsina I. Mental health and alcohol, drugs and tobacco: a review of the comorbidity between mental disorders and the use of alcohol, tobacco and illicit drugs. Drug Alcohol Rev. 2006;25. https://doi.org/10.1080/09595230600944461

14. Rush B, Koegl CJ. Prevalence and profile of people with co-occurring mental and substance use disorders within a comprehensive mental health system. Can J Psychiatry. 2008;53(12):810-21. https://doi.org/10.1177/070674370805301207

15. Wüsthoff LE, Waal H, Ruud T, Gråwe RW. A cross-sectional study of patients with and without substance use disorders in community mental health centres. BMC Psychiatry. 2011;11(93). https://doi.org/10.1186/1471-244X-11-93

16. Mueser KT, Yarnold PR, Rosenberg SD, Swett C Jr, Miles KM, Hill D. Substance use disorder in hospitalized severely mentally ill psychiatric patients: prevalence, correlates, and subgroups. Schizophr Bull. 2000;26(1):179-92. https://doi.org/10.1093/oxfordjournals.schbul.a033438

17. Clausen H, Ruud T, Odden S, Šaltyte Benth J, Heiervang KS, Stuen HK, et al. Hospitalisation of severely mentally ill patients with and without problematic substance use before and during assertive community treatment: an observational cohort study. BMC Psychiatry. 2016;16(1):125. https://doi.org/10.1186/s12888-016-0826-5

18. Reininghaus U, Dutta R, Dazzan P, Doody GA, Fearon P, Lappin J, et al. Mortality in schizophrenia and other psychoses: a 10-year follow-up of the $\mathbb{E}$ ESOP first-episode cohort. Schizophr Bull. 2014;41(3):664-73. https://doi.org/10.1093/schbul/sbu138

19. van Dijk D, Koeter MW, Hijman R, Kahn RS, van den Brink W. Effect of cannabis use on the course of schizophrenia in male patients: a prospective cohort study. Schizophr Res. 2012;137(1-3):50-7.

20. van Wamel A, van Rooijen S, Kroon H. Integrated treatment: the model and European experiences. In: Dom G, Moggi F, editors. Co-occurring addictive and psychiatric disorders. Heidelberg: Springer; 2015. p. 28-45.

21. Lindahl AK. The Norwegian health care system, 2015. In: Mossialos E, Wentzl M, Osborn R, Sarak D, editors. International profiles of health care systems, 2015. New York: The Commonwealth Fund; 2016. p. 133-41.

22. Drake RE, Osher FC, Wallach MA. Alcohol use and abuse in schizophrenia: a prospective community study. J Nerv Ment Dis. 1989;177(7):408-18.

23. Knudsen P, Vilmar T. Cannabis and neuroleptic agents in schizophrenia. Acta Psychiatr Scand. 1984;69(2):162-74.

24. Hansen SS, Munk-Jørgensen P, Guldbæk B, Solgård T, Lauszus KS, Albrechtsen N, et al. Psychoactive substance use diagnoses among psychiatric in-patients. Acta Psychiatr Scand. 2000;102(6):432-8. 
https://doi.org/10.1034/j.1600-0447.2000.102006432.x

25. Sundström C, Petersén E, Sinadinovic K, Gustafsson P, Berman AH. Identification and management of alcohol use and illicit substance use in outpatient psychiatric clinics in Sweden: a national survey of clinic directors and staff. Addict Sci Clin Pract. 2019;14(1):10. https://doi.org/10.1186/s13722019-0140-x

26. Wüsthoff LE, Waal H, Ruud T, Røislien J, Gråwe RW. Identifying co-occurring substance use disorders in community mental health centres. Tailored approaches are needed. Nord J Psychiatry. 2011;65(1):58-64. https://doi.org/10.3109/08039488.2010.489954

27. Norwegian Board of Health. Oppsummering av landsomfattende tilsyn i 2017-2018 med spesialisthelsetjenester for pasienter med psykiske lidelser og mulig samtidig ruslidelse. [Summary of nationwide supervision in 2017-2018 with specialized health services for patients with mental disorders and possible co-occurring substance use disorders]. Norwegian Board of Health. https://www.helsetilsynet.no/publikasjoner/rapport-fra-helsetilsynet/2019/sammenfatning-av-funnfra-to-landsomfattende-tilsyn-i-2017-2018-med-tjenester-til-personer-med-psykiske-lidelser-ogsamtidig-rusmiddelproblem-eller-mulig-samtidig-ruslidelse/. Accessed 14 Nov 2019.

28. Chung RK, Large MM, Starmer GA, Tattam BN, Paton MB, Nielssen OB. The reliability of reports of recent psychoactive substance use at the time of admission to an acute mental health unit. J Dual Diagn. 2009;5(3-4):392-403.

29. Gilchrist G, Moskalewicz J, Slezakova S, Okruhlica L, Torrens M, Vajd R, Baldacchino A. Staff regard towards working with substance users: a European multi-centre study. Addiction. 2011;106(6):111425. https://doi.org/10.1111/j.1360-0443.2011.03407.x

30. Burns JK. Pathways from cannabis to psychosis: a review of the evidence. Front Psychiatry. 2013;4:128.

31. Cerdá M, Sagdeo A, Galea S. Co-morbid forms of psychopathology: key patterns and future research directions. Epidemiol Rev. 2008;30(1):155-77. https://doi.org10.1093/epirev/mxn003

32. Torvik FA, Rosenström TH, Gustravson K, Ystrom E, Kendler KS, Bramness JG, et al. Explaining the association between anxiety disorders and alcohol use disorder: a twin study. Depress Anxiety. 2019;1-11. https://doi.org/10.1002/da.22886

33. Ikeda M, Okahisa Y, Aleksic B, Won M, Kondo N, Naruse N, et al. Evidence for shared genetic risk between methamphetamine-induced psychosis and schizophrenia. Neuropsychopharmacology. 2013;38(10):1864. https://doi.org/doi:10.1038/npp.2013.94

34. Khokhar JY, Dwiel LL, Henricks AM, Doucette WT, Green A. The link between schizophrenia and substance use disorder: a unifying hypothesis. Schizophr Res. 2018;194:78-85. https://doi.org/10.1016/j.schres.2017.04.016

35. Green Al, Tohen MF, Hamer RM, Strakowski SM, Lieberman JA, Glick I, et al. First episode schizophrenia-related psychosis and substance use disorders: acute response to olanzapine and haloperidol. Schizophr Res. 2004;66(2-3):125-35. https://doi.org/10.1016/j.schres.2003.08.001 
36. Robinson J, Sareen J, Cox BJ, Bolton J. Self-medication of anxiety disorders with alcohol and drugs: results from a nationally representative sample. J Anxiety Disord. 2009;23(1):38-45.

37. Turner S, Mota N, Bolton J, Sareen J. Self-medication with alcohol or drugs for mood and anxiety disorders: A narrative review of the epidemiological literature. Depress Anxiety. 2018;35(9):851-60. doi:10.1002/da.22771

\section{Tables}

Table 1 Prevalence of substance use among in-patients and outpatients

\begin{tabular}{|c|c|c|c|c|c|}
\hline Psychiatric disorders & $\mathbf{N}$ & $\begin{array}{r}\text { Men } \\
\text { (\%) }\end{array}$ & $\begin{array}{r}\text { Any substance use } \\
\text { females (\%) }\end{array}$ & $\begin{array}{r}\text { Any substance use } \\
\text { males (\%) }\end{array}$ & $\begin{array}{r}\text { Any substance } \\
\text { use (\%) }\end{array}$ \\
\hline \multicolumn{6}{|c|}{ In-patients } \\
\hline Schizophrenia & 601 & 69.9 & 25.1 & 50.0 & 42.6 \\
\hline Other psychoses & 235 & 49.3 & 24.3 & 29.5 & 27.2 \\
\hline Bipolar disorder & 222 & 38.5 & 13.4 & 39.3 & 24.3 \\
\hline Depression & 340 & 34.6 & 21.9 & 30.2 & 24.7 \\
\hline Anxiety & 62 & 43.5 & 34.3 & 55.6 & 43.5 \\
\hline \multicolumn{6}{|l|}{ Post-traumatic stress } \\
\hline disorder & 75 & 20.0 & 31.7 & 40.0 & 33.3 \\
\hline Eating disorders & 71 & 1.4 & 10.1 & 0.0 & 9.9 \\
\hline Personality disorders & 84 & 33.8 & 37.7 & 51.9 & 42.9 \\
\hline \multicolumn{6}{|l|}{ Other psychiatric } \\
\hline disorders & 668 & 48.2 & 26.2 & 38.0 & 31.4 \\
\hline Total & 2358 & 48.0 & 24.0 & 42.0 & 32.4 \\
\hline \multicolumn{6}{|c|}{ Outpatients } \\
\hline Schizophrenia & 1641 & 64.2 & 14.9 & 31.2 & 25.7 \\
\hline Other psychoses & 840 & 47.9 & 15.8 & 23.7 & 19.5 \\
\hline Bipolar disorder & 1604 & 37.2 & 9.2 & 18.2 & 12.7 \\
\hline Depression & 5253 & 32.9 & 8.0 & 15.8 & 10.6 \\
\hline Anxiety & 2438 & 35.3 & 8.1 & 16.7 & 11.0 \\
\hline \multicolumn{6}{|l|}{ Post-traumatic stress } \\
\hline Eating disorders & 761 & 3.2 & 8.1 & 12.5 & 8.3 \\
\hline Personality disorders & 1670 & 27.4 & 13.4 & 16.4 & 14.3 \\
\hline \multicolumn{6}{|l|}{ Other psychiatric } \\
\hline disorders & 7481 & 40.0 & 11.1 & 21.9 & 15.3 \\
\hline Total & 23167 & 36.9 & 10.1 & 20.0 & 13.9 \\
\hline
\end{tabular}

Table 2 Psychiatric diagnosis and most frequently used drug type among in-patients and outpatients in mental health services 


\begin{tabular}{|c|c|c|c|c|c|c|c|}
\hline \multirow[t]{2}{*}{ Psychiatric disorders } & \multicolumn{2}{|c|}{ Alcohol Opioids } & \multirow[t]{2}{*}{ Cannabis } & \multicolumn{2}{|c|}{ Sedatives Stimulants } & $\begin{array}{r}\begin{array}{r}\text { Multiple drug } \\
\text { use }\end{array} \\
\end{array}$ & \multirow[t]{2}{*}{$\begin{array}{r}\text { Any substance } \\
\text { use }\end{array}$} \\
\hline & \multicolumn{5}{|c|}{ In-patients $(\mathrm{n}=2,358)$} & & \\
\hline Schizophrenia & 8.7 & 5.3 & 23.8 & 9.0 & 20.8 & 23.3 & 42.6 \\
\hline Other psychoses & 7.2 & 3.0 & 13.6 & 8.1 & 10.2 & 13.6 & 27.2 \\
\hline Bipolar & 11.3 & 1.4 & 7.7 & 8.1 & 4.5 & 7.7 & 24.3 \\
\hline Depression & 10.6 & 0.3 & 3.8 & 12.9 & 1.8 & 5.3 & 24.7 \\
\hline Anxiety & 19.4 & 0.0 & 3.2 & 21.0 & 1.6 & 9.7 & 43.5 \\
\hline $\mathrm{PTSD}^{1}$ & 14.7 & 4.0 & 6.7 & 17.3 & 5.3 & 12.0 & 33.3 \\
\hline Eating disorders & 4.2 & 0.0 & 5.6 & 1.4 & 1.4 & 2.8 & 9.9 \\
\hline Personality disorders & 10.7 & 3.6 & 11.9 & 17.9 & 11.9 & 13.1 & 42.9 \\
\hline $\begin{array}{l}\text { Other psychiatric } \\
\text { diagnoses }\end{array}$ & 10.6 & 2.2 & 9.7 & 11.8 & 7.6 & 12.3 & 31.4 \\
\hline \multirow[t]{2}{*}{ Total } & 10.0 & 2.7 & 12.3 & 10.9 & 9.8 & 13.4 & 32.4 \\
\hline & \multicolumn{7}{|c|}{ Outpatients $(\mathrm{n}=23,167)$} \\
\hline Schizophrenia & 8.8 & 2.4 & 9.2 & 5.1 & 11.2 & 12.1 & 25.7 \\
\hline Other psychoses & 6.8 & 0.4 & 7.6 & 5.2 & 4.6 & 5.2 & 19.5 \\
\hline Bipolar disorder & 7.2 & 0.2 & 3.5 & 2.4 & 0.9 & 2.1 & 12.7 \\
\hline Depression & 6.1 & 0.2 & 1.9 & 2.8 & 0.6 & 1.4 & 10.6 \\
\hline Anxiety & 5.0 & 0.3 & 2.2 & 4.0 & 0.8 & 1.7 & 11.0 \\
\hline PTSD $^{1}$ & 3.9 & 0.5 & 2.7 & 3.4 & 1.1 & 1.7 & 10.2 \\
\hline Eating disorders & 5.1 & 0.1 & 2.1 & 1.2 & 0.5 & 1.1 & 8.3 \\
\hline Personality disorders & 6.2 & 0.4 & 3.8 & 4.4 & 2.0 & 3.1 & 14.3 \\
\hline $\begin{array}{l}\text { Other psychiatric } \\
\text { diagnoses }\end{array}$ & 6.6 & 0.9 & 5.1 & 4.1 & 2.4 & 3.8 & 15.3 \\
\hline Total & 6.3 & 0.6 & 4.0 & 3.7 & 2.2 & 3.3 & 13.9 \\
\hline
\end{tabular}

1 Post-traumatic stress disorder

Table 3 Demographic and socio-demographic characteristics of patients in mental health services with substance use 


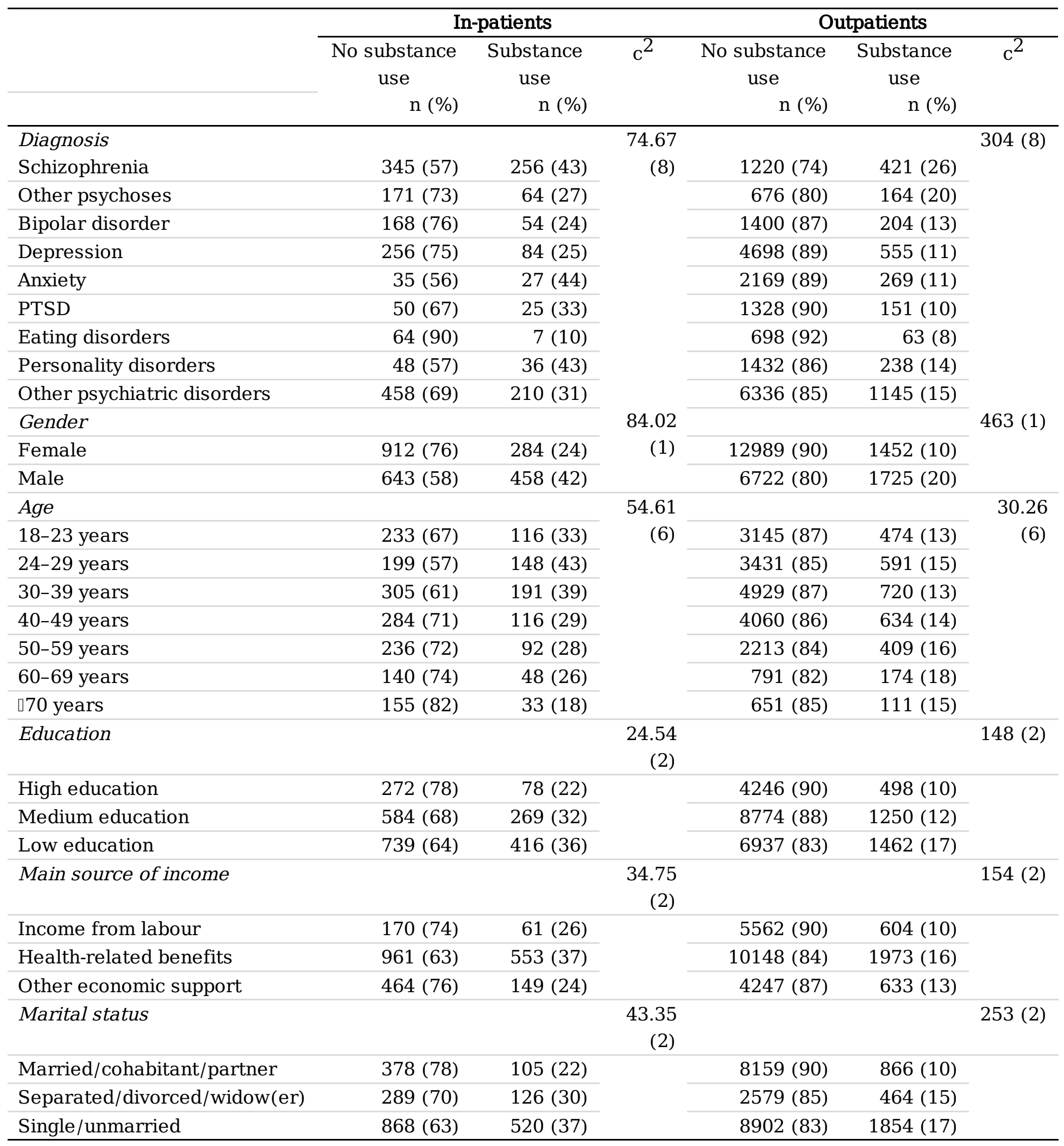

Note. All chi-square tests: $p<0.0001$ 
Table 4 Regression results (logit) where the dependent variable is 0 (no co-occurring substance use) or 1 (co-occurring substance use) showing odds ratios and standard errors for in-patients $(\mathrm{N}=2,358)$ and outpatients $(\mathrm{N}=23,167)$ 


\begin{tabular}{|c|c|c|c|c|c|c|}
\hline & \multicolumn{3}{|c|}{ In-patients } & \multicolumn{3}{|c|}{ Outpatients } \\
\hline & Model 1 & Model 2 & Model 3 & Model 1 & Model 2 & Model 3 \\
\hline \multicolumn{7}{|l|}{ Diagnosis: Base (Schizophrenia) } \\
\hline \multirow[t]{2}{*}{ Other psychoses } & $0.50 * * *$ & $0.55^{* * *}$ & $0.61 * * *$ & $0.70 * * *$ & $0.78^{* *}$ & 0.88 \\
\hline & {$[0.085]$} & {$[0.100]$} & {$[0.11]$} & {$[0.073]$} & {$[0.084]$} & {$[0.095]$} \\
\hline \multirow[t]{2}{*}{ Bipolar disorder } & $0.43^{* * *}$ & $0.57 * * *$ & $0.67 * *$ & $0.42^{* * *}$ & $0.49 * * *$ & $0.66^{* * *}$ \\
\hline & {$[0.077]$} & {$[0.11]$} & {$[0.13]$} & {$[0.040]$} & {$[0.048]$} & {$[0.067]$} \\
\hline \multirow[t]{2}{*}{ Depression } & $0.44^{* * *}$ & $0.68 * *$ & 0.83 & $0.34 * * *$ & $0.43^{* * *}$ & $0.61^{* * *}$ \\
\hline & {$[0.067]$} & {$[0.11]$} & {$[0.15]$} & {$[0.025]$} & [0.032] & {$[0.048]$} \\
\hline \multirow[t]{2}{*}{ Anxiety } & 1.04 & 1.54 & $1.82^{* *}$ & $0.36^{* * *}$ & $0.45^{* * *}$ & $0.63^{* * *}$ \\
\hline & {$[0.28]$} & {$[0.43]$} & {$[0.53]$} & {$[0.031]$} & {$[0.040]$} & [0.058] \\
\hline \multirow[t]{2}{*}{ Post-traumatic stress disorder } & 0.67 & 0.98 & 1.24 & $0.33^{* * *}$ & $0.43^{* * *}$ & $0.59 * * *$ \\
\hline & {$[0.17]$} & {$[0.26]$} & {$[0.34]$} & {$[0.034]$} & {$[0.046]$} & {$[0.064]$} \\
\hline \multirow[t]{2}{*}{ Eating disorders } & $0.15^{* * *}$ & $0.21 * * *$ & $0.27 * * *$ & $0.26^{* * *}$ & $0.42^{* * *}$ & $0.58^{* * *}$ \\
\hline & {$[0.060]$} & {$[0.091]$} & {$[0.12]$} & {$[0.037]$} & {$[0.064]$} & [0.090] \\
\hline \multirow[t]{2}{*}{ Personality disorders } & 1.01 & 1.39 & 1.39 & $0.48^{* * *}$ & $0.63^{* * *}$ & $0.79 * *$ \\
\hline & {$[0.24]$} & {$[0.35]$} & {$[0.36]$} & {$[0.043]$} & {$[0.060]$} & {$[0.076]$} \\
\hline \multirow[t]{2}{*}{ Other psychiatric disorders } & $0.62 * * *$ & 0.83 & 1.02 & $0.52^{* * *}$ & $0.64 * * *$ & $0.86^{* *}$ \\
\hline & {$[0.072]$} & {$[0.10]$} & {$[0.14]$} & {$[0.034]$} & {$[0.043]$} & [0.062] \\
\hline \multicolumn{7}{|l|}{ Gender: Base (female) } \\
\hline \multirow[t]{2}{*}{ Male } & & $1.99 * * *$ & $1.98^{* * *}$ & & $2.13^{* * *}$ & $1.99 * * *$ \\
\hline & & {$[0.20]$} & {$[0.20]$} & & {$[0.086]$} & {$[0.082]$} \\
\hline \multicolumn{7}{|l|}{ Age: Base (18-23 years) } \\
\hline \multirow[t]{2}{*}{ 24-29 years } & & $1.37 *$ & $1.33^{*}$ & & 1.09 & $1.26^{* * *}$ \\
\hline & & {$[0.23]$} & {$[0.23]$} & & {$[0.074]$} & [0.090] \\
\hline \multirow[t]{2}{*}{ 30-39 years } & & 1.15 & 1.15 & & $0.89 *$ & 1.12 \\
\hline & & {$[0.18]$} & {$[0.19]$} & & {$[0.058]$} & [0.081] \\
\hline \multirow[t]{2}{*}{$40-49$ years } & & 0.82 & 0.81 & & 0.94 & $1.19 * *$ \\
\hline & & {$[0.14]$} & {$[0.15]$} & & {$[0.063]$} & {$[0.091]$} \\
\hline \multirow[t]{2}{*}{$50-59$ years } & & 0.81 & 0.78 & & 1.12 & $1.41^{* * *}$ \\
\hline & & {$[0.14]$} & {$[0.15]$} & & {$[0.084]$} & {$[0.12]$} \\
\hline \multirow[t]{2}{*}{$60-69$ years } & & 0.83 & 0.86 & & $1.31 * * *$ & $1.65^{* * *}$ \\
\hline & & {$[0.18]$} & {$[0.20]$} & & {$[0.13]$} & [0.18] \\
\hline \multirow[t]{2}{*}{$\square 70$ years } & & $0.50 * * *$ & $0.55^{* *}$ & & 1.11 & $1.47^{* * *}$ \\
\hline & & {$[0.12]$} & {$[0.15]$} & & {$[0.13]$} & {$[0.19]$} \\
\hline \multicolumn{7}{|l|}{ Education: Base (High education) } \\
\hline \multirow[t]{2}{*}{ Medium education } & & & 1.21 & & & 1.03 \\
\hline & & & {$[0.20]$} & & & {$[0.062]$} \\
\hline Low education & & & $1.52 * *$ & & & $1.36^{* * *}$ \\
\hline & & & {$[0.25]$} & & & {$[0.085]$} \\
\hline Income: Base (Income from lab & & & & & & \\
\hline Health-related benefits & & & $1.37 *$ & & & $1.39 * * *$ \\
\hline & & & {$[0.25]$} & & & {$[0.076]$} \\
\hline Other economic support & & & 1.00 & & & $1.15^{* *}$ \\
\hline & & & {$[0.21]$} & & & {$[0.080]$} \\
\hline Marital status: Base (Married/c & & & & & & \\
\hline Separated/divorced/widow(er) & & & $1.81^{* * *}$ & & & $1.46^{* * *}$ \\
\hline & & & {$[0.30]$} & & & {$[0.097]$} \\
\hline
\end{tabular}


Constant

$0.74^{* * *} \quad 0.43^{* * *} \quad 0.18^{* * *}$

$0.35^{* * *}$

$0.20 * * *$

Standard error in parentheses. $* * * \mathrm{p}<0.01, * * \mathrm{p}<0.05, * \mathrm{p}<0.1$.

\section{Figures}

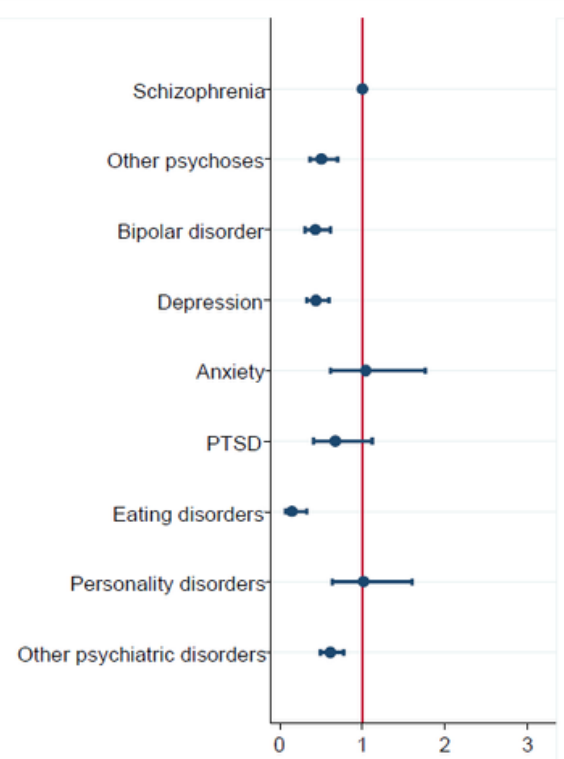

OR substance use, Model 1

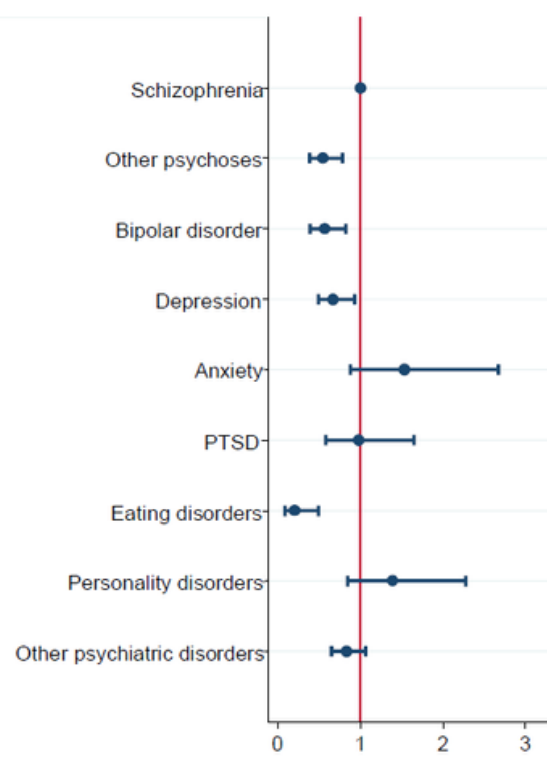

OR substance use, Model 2

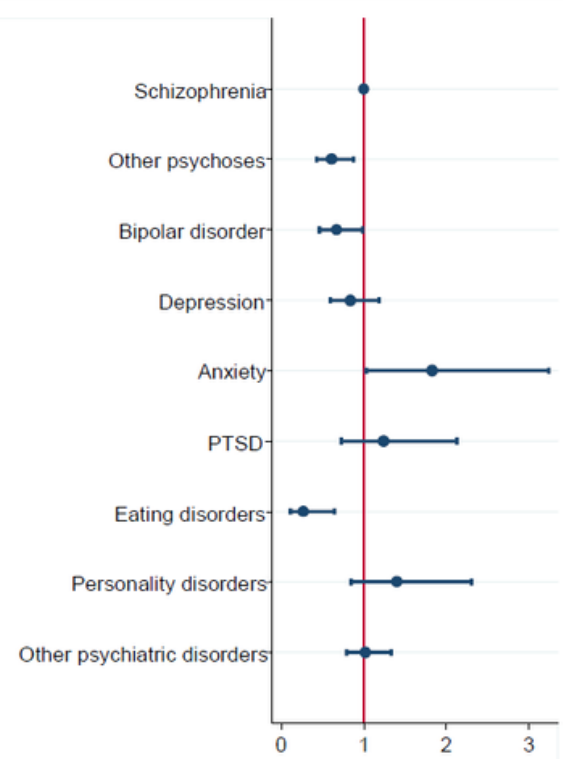

OR substance use, Model 3

\section{Figure 1}

Regression results showing odds ratios and confidence intervals for in-patients: Model 1 (diagnoses only), Model 2 (diagnoses, gender and age), Model 3 (diagnoses, gender and age, level of education, main source of income and marital status), $\mathrm{N}=2358$. 

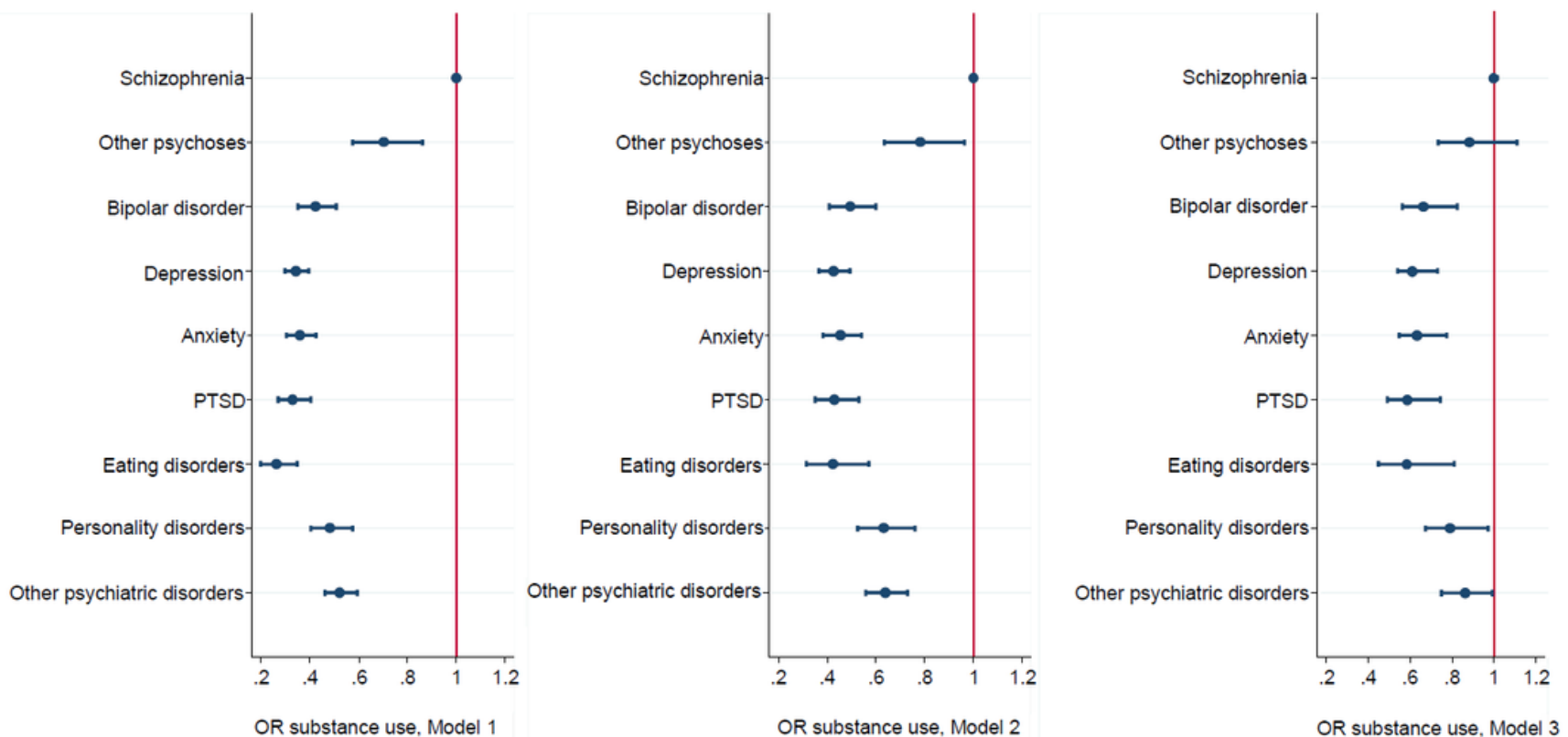

\section{Figure 2}

Regression results showing odds ratios and confidence intervals for outpatients: Model 1 (diagnoses only), Model 2 (diagnoses, gender and age), Model 3 (diagnoses, gender and age, level of education, main source of income and marital status), $N=23,167$. 